\title{
TRACKING TIME ADJUSTMENT IN BACK CALCULATION ANTI-WINDUP SCHEME
}

\author{
Hayk Markaroglu Mujde Guzelkaya Ibrahim Eksin Engin Yesil \\ Istanbul Technical University, Faculty of Electrical and Electronics Engineering, \\ Control Engineering Department, \\ Maslak, TR-34469, Istanbul, Turkey \\ E-mail:yesil@elk.itu.edu.tr
}

\section{KEYWORDS}

PID controller, saturation in process control, integral windup, back calculation scheme

\begin{abstract}
This study deals with the tuning of the tracking time parameter in the back calculation anti-windup scheme. When the controller output saturates, the back calculation method does not reset the integral action instantaneously but rather dynamically with a time constant $T_{t}$. Here, a method is presented to adjust the parameter $T_{t}$ in such a way that the process output acquires a 'good' performance. The proposed method exploits the advantageous sides of 'big' and 'small' values of $T_{t}$ and the value of the parameter $T_{t}$ is determined based on the parameters of the preferred process model. In addition to this approach, the optimal value of this tracking time parameter is searched using a basic genetic search algorithm with Integral Time Absolute Error (ITAE) criterion. Finally, the simulation results of back calculation algorithm that uses $T_{t}$ adjusted by the proposed method and $T_{t}$ determined through a genetic search algorithm are compared with each other.
\end{abstract}

\section{INTRODUCTION}

Even though many effective control strategies have been achieved in recent years, proportional-integralderivative (PID) controllers are still the most adopted controllers in industrial settings. They provide a more preferable cost/benefit ratio when compared with other techniques. However, the presences of nonlinear effects limit their performances and also cause the well-known phenomenon of integrator windup. All physical systems are subject to actuator saturation since all actuators have limitations. Actuator limits cause a nonlinear effect that can be expressed by a saturation term, and this nonlinearity is one of the major reasons of integral windup.

There have been several studies and attempts to overcome integrator windup during the last three decades. One of the earliest ones was the work by (Fertik and Ross 1967). Their strategy has been one of the most popular anti-windup schemes and has various names as anti-reset windup, back calculation and tracking and integrator resetting. Khanderia and Luyben have studied experimental evaluation of several digital algorithms for anti-reset windup (Khanderia and Luyben 1976). Doyle stated the fact that any controller with slow or unstable modes will face windup problems if there are actuator constraints (Doyle and Packard 1987a, Doyle et al. 1987b). He further introduced the extension of anti-reset windup to a general class of controllers, which is often referred to as high gain conventional anti-windup (CAW). Hanus and coworkers introduced the conditioning technique as a generalized way of back calculation strategy (Hanus et al. 1987, Hanus and Kinnaert 1989, Hanus and Peng 1992). Åstrom and co-workers proposed an observer based methodology to restore the consistency between the saturated controller signal and the controller states (Åström and Wittenmark 1984, Åström and Rundqwist 1989). Walgama and Sternby have exposed this inherent observer property in several anti-windup schemes (Walgama and Sternby 1990, Walgama et al. 1992). Campo and Morari have derived the Hanus conditioning technique as a special case of the observerbased approach (Campo and Morari 1990). A modified Internal Model Control (IMC) implementation has been proposed by Zheng to improve the performance of antiwindup techniques (Zheng et al. 1995). Kothare introduced a unified framework for anti-windup design studies and claimed that prior proposed techniques were all only a special form of a generalized problem (Kothare et al. 1994). He further explained a simple method for defining that general problem. Visioli introduced a combined scheme of conditional integration and back calculation to eliminate integrator windup in systems with transport delay (Visioli 2003). Hansson was one of the few who tried employing fuzzy logic techniques for anti-windup design (Hansson et al. 1994). An evolutionary design procedure for discrete time anti-windup controller for electrical drives is proposed in (Cupertino et al. 2004).

This study concerns with the tuning parameter of the back calculation anti windup scheme proposed by (Fertik and Ross 1967). When the controller output saturates, the back calculation does not reset the integral instantaneously but dynamically with a time constant $T_{t}$. This constant is the tuning parameter of the method that 
governs how quickly the integral term is reset and therefore the selection of this parameter has a visible and considerable effect on the process performance. Here, we present a method to adjust the parameter $T_{t}$ in such a way that the process output acquires a 'good' performance. The method gathers up the advantages of big and small values of $T_{t}$ and determines the value of the parameter $T_{t}$ using the parameters of the process model preferred. The simulation results of back calculation scheme that uses $T_{t}$ adjusted by the proposed method and $T_{t}$ determined through a genetic search algorithm are compared with each other.

\section{INTEGRATOR WINDUP}

For a control system with a wide range of operating conditions, it may happen that the control variable reaches the actuator limits (Åström and Hagglund 1995). Moreover, switching between operating modes, which results as the substitution of the controller input, concludes in the same way. These facts break the feedback loop and disable control issues on the system, as the actuator will remain at its limit value independently of the process output. If the controller has integral part, the error will continue to be integrated. This means that the integral term may become very large or, in other terms, it winds up. Then, it is required that the error has opposite sign for a long period before the operations on the system return to normal. Briefly, any controller with integral action may give large transients when the actuator saturates or plant input substitution occurs. The controller does not drive the plant under those circumstances and as a result, the states of the controller are wrongly updated (Åström and Rundqwist 1989). The effect of windup is in the form of significant performance deterioration; large overshoots in the output and sometimes-even instability.

Wide ranges of controllers that are used in industrial applications are mostly PID types. To deal with integrator windup phenomenon, controller parameters are designed ignoring the actuator constraints and added an anti-windup compensator in the integral part of the controller (Visioli 2003).

\section{BACK CALCULATION METHOD}

In the back calculation method, when the controller output saturates, the integral is recomputed so that its new value gives an output at the saturation limit. It is advantageous not to reset the integrator instantaneously but dynamically with a time constant $T_{t}$.

Fig. 1 shows the block diagram for back calculation method where Ref and y represent the reference and the process output. The control system has an extra feedback path that is generated by measuring the difference between the actual actuator output $(v)$ and the controller output $(u)$ and forming an error signal $e_{s}$. This error signal is then fed back to the integrator through gain $1 / T_{t}$. The signal is zero when there is no saturation. Thus, it will not have any effect on the normal operation when the actuator does not saturate. When the actuator saturates, the signal $e_{s}$ is different from zero. The normal feedback path around the process is broken because the process input remains constant. There is, however, a feedback path around the integrator. Because of this, the integrator output is driven towards a value such that the integrator input becomes zero.

Tracking time constant has a visible effect on system performance when back calculation is employed. $T_{t}$ governs how quickly the integral term is reset. Smaller tracking time constants reset integrator quicker, which may seem to be an advantage at first. Hence, general rule implies that tracking time constant should be between integrator time constant and derivative time constant. A rule of thumb that has been suggested is to choose $\mathrm{T}_{\mathrm{t}}=\sqrt{\mathrm{T}_{\mathrm{i}} \cdot \mathrm{T}_{\mathrm{d}}}$ where $T_{i}$ and $T_{d}$ are the integrator and the derivative time constants of the PID controller, respectively (Åström and Hagglund 1995).

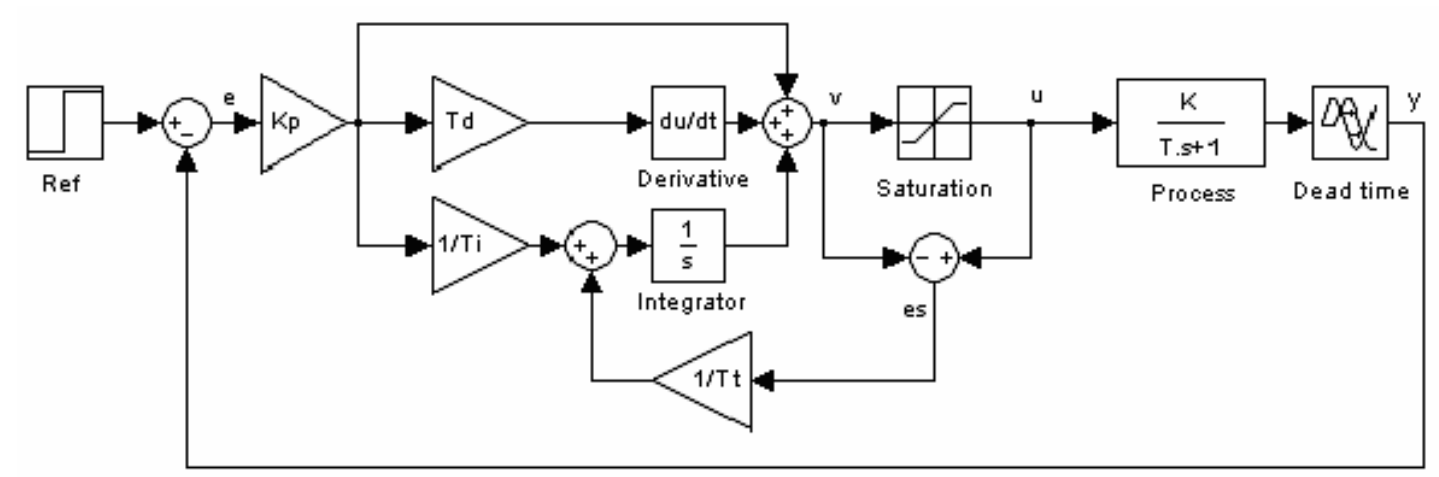

Figure 1: Block diagram of the back calculation anti windup scheme 


\section{TRACKING TIME ADJUSTMENT}

As it is mentioned above, an empiric expression can be used for the selection of the parameter $T_{t}$ for PID controllers. Such kind of a rule of thumb it does not exist for PI controllers. However, $T_{t}$ can be chosen equal to the integral time constant $T_{i}$ at the beginning and then it may be increased or decreased manually in order to achieve a fine-tuning. Small values (with respect to the required value) chosen for $T_{t}$ decrease the saturation time of the controller output and also the settling time of the process. In that case, the process response will be slow and will not produce an overshoot. Big values (with respect to the required value) chosen for $T_{t}$ provide a long saturation time at the controller output and it will also produce over-shoots in the system response; that is, the system response will be fast but with an over-shoot.

Another way in setting the parameter $T_{t}$ is that it can be searched by running a global search algorithm through a proper cost function is chosen.

The procedure given in this study for the adjustment of the parameter $T_{t}$ is generated in such a way that the advantages of choosing 'big' or 'small' values for $T_{t}$ are both exploited. The main principles can be expressed as follows:

$i$. If the controller output is in saturation, $\mathrm{T}_{\mathrm{t}}$ is chosen very big until the system output reaches to a certain percentage value $(\% \mathrm{c})$ of system reference. Hence the effect of the feedback through the gain $1 / T_{t}$ is lessened as much as possible. This causes a long stay in saturation and also a very fast increase in the process response. The problem at this stage is the determination of the percentage value $\mathrm{c}$.

ii. If the process output reaches to the predetermined percentage value, this time, $T_{t}$ is decreased to a $T_{t}^{\text {new }}$ value so that the effect of the feedback through the gain $1 / T_{t}^{\text {new }}$ is activated. As the integral action is suppressed, very big over-shoots will not occur at the process output. Suitable $T_{t}^{\text {new }}$ values have to be determined for different types of systems.

In order to determine process parameters dependent $\mathrm{c}$ and $T_{t}^{\text {new }}$ values, the systems are expressed by the following first-order dead-time system transfer function

$$
G(s)=\frac{K}{T s+1} e^{-L \cdot s}
$$

where $T, K$ and $L$ represent the time constant, openloop system gain and dead-time, respectively. Transfer functions of high order processes might also be transformed to the transfer function given in Equation (1) using the phenomenon presented in (Skosgestad 2002).

Ziegler-Nichols tuning rules are used to determine the PI type controller parameters and the proportional gain
$\left(K_{p}\right)$ and integral time constant $\left(T_{i}\right)$ of the controller are obtained as follows:

$$
\mathrm{K}_{\mathrm{p}}=\frac{0.9 \cdot \tau}{\mathrm{K} \cdot \mathrm{L}} ; \quad \mathrm{T}_{\mathrm{i}}=3.33 \cdot \mathrm{L}
$$

\section{Determination of the Percentage Value $(\% c)$ of the System Reference}

As it is explained above, the value of $T_{t}$ has to be changed when the process response reaches to a percentage value $(\% c)$ of the reference value. After some tests that has been performed with different types of process models, we have seen that this percentage value depends on the open-loop gain $K$ and the maximum value of saturated controller output $u_{\max }$; so that, this value can be determined using an empirical formula that has been derived by the aid of the contents of Table 1. The empirical formula that provides the value of $c$, is quite easily derived by fitting a linear curve using the values in the two rows of the Table 1 as in Equation (3).

Table 1: The variation of $u_{\max } . K$ against the value of $\mathrm{c}$ for $\operatorname{Ref}=1$.

\begin{tabular}{|c|c|c|c|c|c|c|c|c|c|c|}
\hline $\boldsymbol{u}_{\max }$ & 1 & 1,2 & 1,4 & 1,6 & 1,8 & 2 & 2,2 & 2,4 & 2,6 & $\infty$ \\
\hline $\boldsymbol{K}$ & 100 & 80 & 70 & 60 & 50 & 40 & 30 & 20 & 10 & 10 \\
\hline
\end{tabular}

$$
\mathrm{c}=\left\{\begin{array}{ccc}
\left(-0.5 \frac{\mathrm{u}_{\max } \cdot \mathrm{K}}{\operatorname{Ref}}+1.4\right) 100 & \text { for } & 1 \leq \frac{\mathrm{u}_{\max } \cdot \mathrm{K}}{\operatorname{Ref}} \leq 2.6 \\
10 & \text { for } & 2.6<\frac{\mathrm{u}_{\max } \cdot \mathrm{K}}{\operatorname{Ref}}
\end{array}\right.
$$

The meta-rule used in this derivation is that: "As the system gain $\mathrm{K}$ and $\mathrm{u}_{\max }$ increases, the process response fastens and the integral action must be decreased at the early stages of the response."

In this formula, if $\frac{\mathrm{u}_{\max } \cdot \mathrm{K}}{\mathrm{Ref}}<1$, a steady-state error is seen at the system response. Therefore, the choice of $\% c$ becomes meaningless. If $\frac{\mathrm{u}_{\max } \cdot \mathrm{K}}{\mathrm{Ref}}>2.6$, it is assumed that $\% c$ can be fixed to the value 10 since the values lower than 10 demonstrated no significant positive changes or effects on the system performance.

\section{The Adjustment of $T_{t}$}

In the derivation phase of a formula for the $T_{t}^{\text {new }}$, various experiments on systems with different $\mathrm{T}$ and $\mathrm{L}$ have been conducted. It has been observed that the empirical formula might be arranged in the linear form of $T_{t}^{\text {new }}=\alpha \cdot T_{i}$. The pale graphic of Fig 2 shows the real data for the variation of $\alpha$ against the ratio $\mathrm{T} / \mathrm{L}$ due to various experiments conducted. The dark graphic of Fig. 2 is the curve that we have fitted to the variation of $\alpha$ and it can be expressed as 


$$
\alpha=\left(0.59-0.65 \cdot e^{-0.09 \frac{T}{L}}\right)
$$

Consequently, the following empirical formula has been deduced for time constant dominant systems, so it provides us the new value of $T_{i}$ denoted by $T_{t}^{\text {new }}$ :

$$
\mathrm{T}_{\mathrm{t}}{ }^{\text {new }}=\left(0.59-0.65 \cdot \mathrm{e}^{-0.09 \frac{\mathrm{T}}{\mathrm{L}}}\right) \cdot \mathrm{T}_{\mathrm{i}}
$$

The meta-rule that has been used in this derivation can be expressed as follows: "As $\mathrm{T}$ and $\mathrm{L}$ decrease, the process response fastens and so the total integral action must be increased."

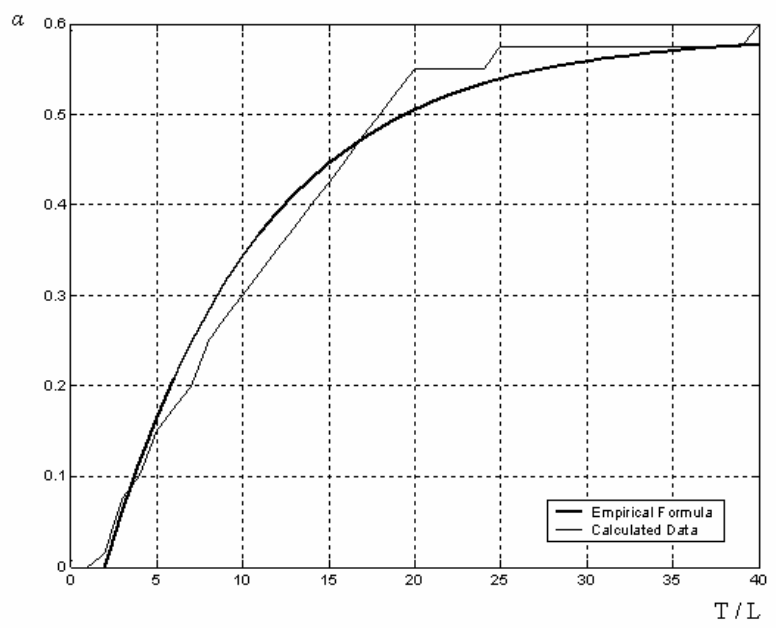

Figure 2: The variation of $\alpha$ against the ratio $\mathrm{T} / \mathrm{L}$

The procedure for the tracking time constant adjustment can be summarized in the following steps:

Step 1: Determine open-loop gain $(K)$, time constant $(T)$ and dead-time $(L)$. (If the system is not of the first order dead-time type system, then transform it to this type.)

Step2: Find the parameters of PI controller using Ziegler-Nichols rules.

Step3: Find the $\% c$ and $T_{t}^{\text {new }}$ values via empirical formulas or optimal global search algorithm.

Step4: When the controller output saturates, set $T_{t}=10 \cdot T_{i}$ up to the time when the system output reaches to $\% c$ of the reference.

Step5: Then, set $T_{t}=T_{t}^{\text {new }}$.

\section{SIMULATIONS RESULTS}

To see the performance of the tracking time adjustment, the following simulations are done in order to be fair in comparison. The results of back calculation with the proposed $T_{t}$ adjustment method are compared with the results of back calculation with constant $T_{t}$ determined by running a genetic search algorithm. The optimization criterion is determined as $\operatorname{ITAE}=\int_{0}^{t} \mathrm{t}|\mathrm{e}(\mathrm{t})| \mathrm{dt}$.

\section{Simulation 1}

In the first simulation, the following first-order process model with a dead-time is considered:

$$
\mathrm{G}(\mathrm{s})=\frac{1}{5 \mathrm{~s}+1} \mathrm{e}^{-\mathrm{s}}
$$

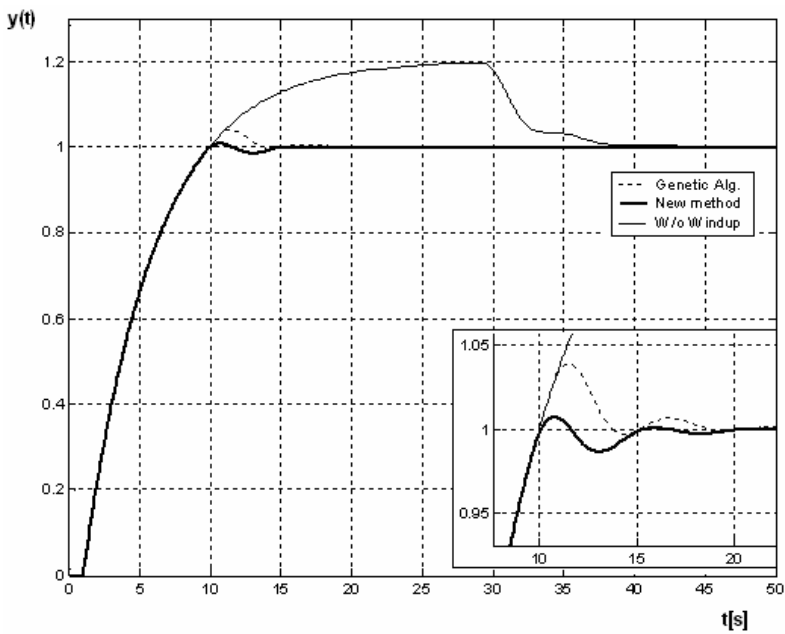

Figure 3a: The illustration of the system responses of the first-order dead-time system

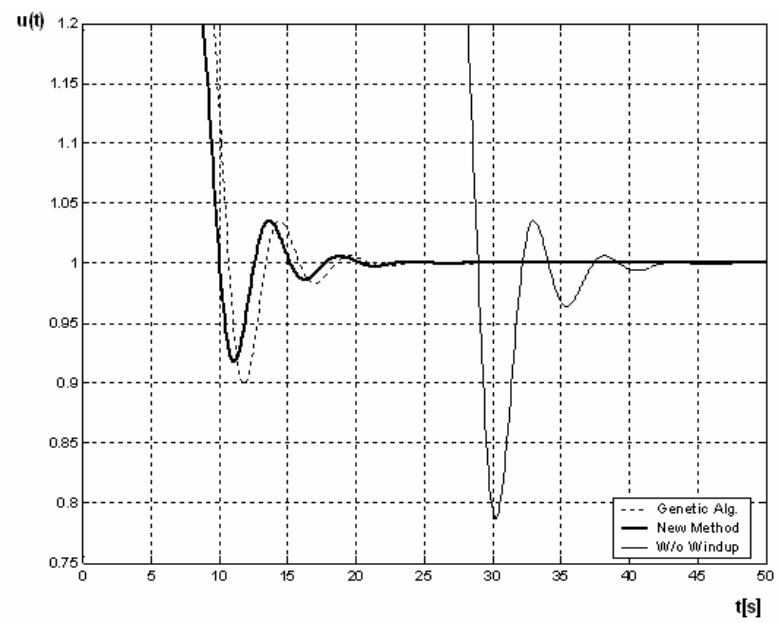

Figure 3b: The illustration of the control signals of the first-order dead-time system

The maximum controller output value is set to 1.2 $\left(u_{\max }=1.2\right)$ and the controller parameters $K_{p}$ and $T_{i}$ are found 4.5 and 3.33 , respectively. The genetic search algorithm has given the constant $T_{t}$ as 3.33. Following the steps given for the new adjustment method, $\% c$ is calculated as \%80 using the Equation (3). $T_{t}$ is set to $10 \cdot T_{i}$ up to the time that the system output reaches to $\% 80$ of the reference value. Then, $T_{t}$ is decreased to the $T_{t}^{\text {new }}$ value that is determined as $0.18 \cdot T_{i}$ using the 
Equation (4). The corresponding system responses and controller outputs are given in Fig.3a and Fig.3b, respectively.

As it is seen from Fig. 3a, the new method provides even better response than the genetic search algorithm. The minimum ITAE value obtained by using back calculation with constant $T_{t}$ (determined by running a genetic search algorithm) is obtained as 13.1; however, the ITAE value obtained by the application of back calculation with the proposed $T_{t}$ adjustment is 12.39 .

\section{Simulation 2}

The second simulation is performed on a fourth-order process with the transfer function given as follows:

$$
G(s)=\frac{(30 s+2)}{(20 s+1)(s+1)(0.1 s+1)^{2}}
$$

This system is than approximated by the following first-order dead time:

$$
\mathrm{G}(\mathrm{s})=\frac{1.5}{(1.05 \mathrm{~s}+1)} \mathrm{e}^{-0.15 \mathrm{~s}}
$$

The maximum controller output value is assumed to be $1.5\left(u_{\max }=1.5\right)$, and then the controller parameters $K_{p}$ and $T_{i}$ are calculated using the approximated system (12) as 4.2 and 0.5 respectively. The genetic search algorithm has determined constant $T_{t}$ as 0.25 . Following the steps given for the new adjustment method, the parameters $T_{t}^{\text {new }}$ and $\% c$ are calculated via empirical formulas as $0.25 \cdot T_{i}$ and $\% 27.5$, respectively. The system responses and controller output are given in Fig.4a and Fig.4b, respectively.

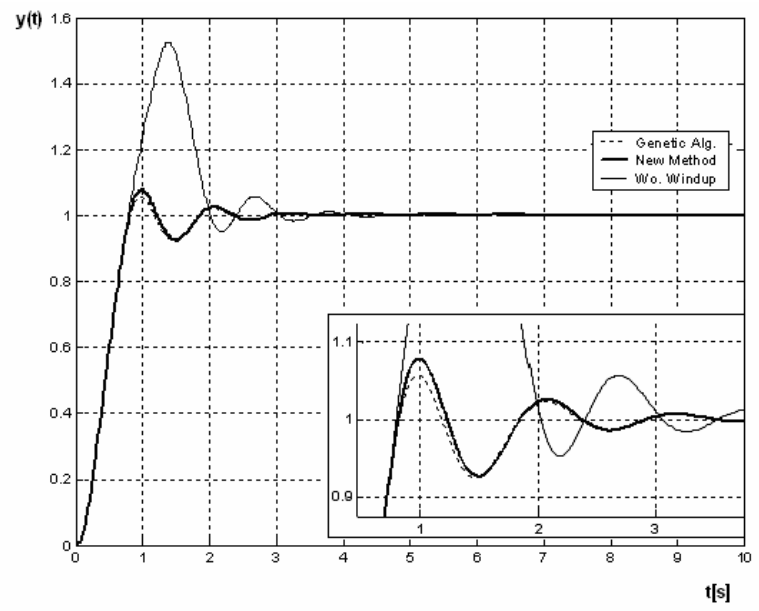

Figure 4a: The illustration of the system responses of the fourth-order system

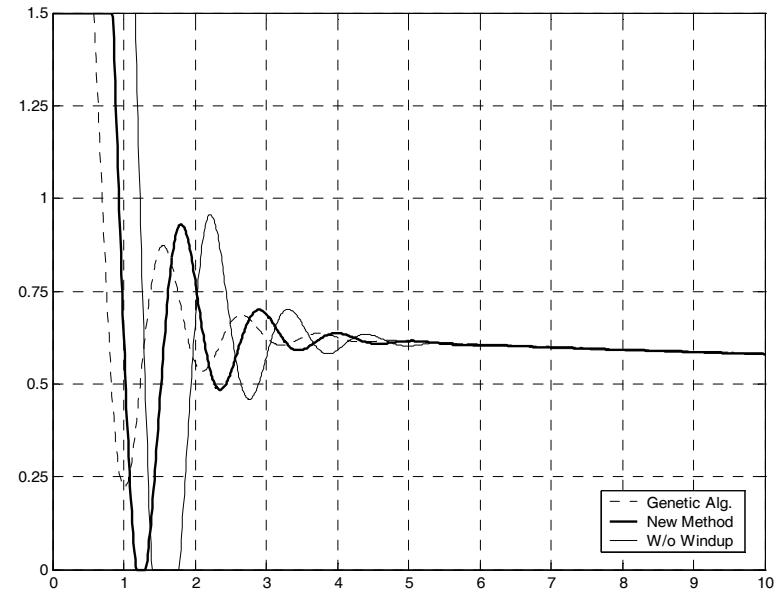

Figure 4b: The illustration of the control signals of the fourth-order system

As seen also from Fig. 4a, in spite of being a highorder system, the new method gives a good and effective performance of system output. ITAE values of the constant $T_{t}$ obtained via a genetic search algorithm and the new adjustment method are 0.2521 and 0.2628 respectively. Even though, the system is of order four, adjustment procedure is applied on a very simplified first order model; whereas, genetic algorithm is used directly on the real forth order system. However, the results of both approaches are satisfactory and they are in comparable levels.

\section{CONCLUSION}

In this study, a method for the adjustment of the tuning parameter of the back calculation anti windup scheme is proposed. The structure of back calculation anti windup scheme is not changed. The proposed method exploits the advantages sides of 'big' and 'small' values of $T_{t}$. and the value of the parameter $T_{t}$ is determined based on the parameters of the preferred process model. The adjustment procedure has two stages. $T_{t}$ is chosen very big until the process output reaches to a certain percentage value $(\% c)$ of system reference. This causes a long stay in saturation and also a very fast increase in the system response. If the system output reaches to the predetermined percentage value, this time, $T_{t}$ is decreased to a $T_{t}^{\text {new }}$ value. As the integral action is suppressed, very big over-shoots are prevented at the process output. Thus, the process is forced to give a fast response with a considerable satisfactory overshoot. For the determination of $\mathrm{c}$ and $T_{t}^{\text {new }}$ two empirical formulas have been derived. Even though, the formulation of the method is based on the first order time delay process models, the results obtained for high order systems are also very satisfactory. 


\section{REFERENCES}

Åström, K.J. and Wittenmark B., 1984. Computer Controlled Systems Theory and Design. Prentice-Hall, Englewood Cliffs, New Jersey.

Åström, K.J. and Rundqwist, L., 1989. "Integrator windup and how to avoid it." In Proc. 1989 Am. Control Confi, Pittsburgh, pp. 1693-1698.

Åström, K.J. and Hagglund, T., 1995. PID Controllers:Theory, design and tuning. ISA Pres, Research Triangle Park, North Carolina.

Campo, P.J. and Morari, M., 1990. "Robust Control of processes subject to saturation nonlinearities." Comput Chem. Engng., 14, 343-358.

Cupertino, F., Mininno E., Naso, D. and Turchiano, B., 2004. "On-line genetic design of anti-windup unstructured controllers for electric drives with variable load." IEEE Trans. on Evl. Comp., 8(4), 347-264.

Doyle, J.C, Smith, R.S. and Enns, D.F., 1987a. "Control of plants with input saturation nonlinearities." In. Proc. 1987 Am. Control Conf, Minneapolis, pp. 1034-1039.

Doyle, J.C. and Packard, A.K., 1987b. "Uncertain multivariable systems from a state space perspective". In Proc. 1987 Am. Control Conf, Minneapolis, pp. 21472152.

Fertik, H.A. and Ross, C.W., 1967. "Direct digital control algorithm with anti-windup feature." ISA Trans., 6, 317328.

Hanus, R., Kinnaert, M. and Henrotte, J.L., 1987. "Conditioning technique, a general anti-windup and bumpless transfer method." Automatica, 23, 729-739.

Hanus, R. and Kinnaert, M., 1989. "Control of constrained multivariable systems using the conditioning technique." In Proc. 1989 Am. Control Conf, Pittsburgh, pp. 17111718.

Hanus, R. and Peng, Y., 1992. "Conditioning technique for controllers with time delays." IEEE Trans. Aut. Control, 37,689-692.

Hansson, A., Gruber, P. and Todtli, J., 1994. "Fuzzy antireset windupfor PID controllers." Control Eng. Pract, 2, 389-396.

Khanderia, J. and Luyben, W.L., 1976. "Experimental evaluation of digital algorithms for anti-reset windup." Ind. Engng Chem., Proc. Des. Dev., 15, 278-285.

Kothare, M.V., Campo, P.J., Morari, M. and Nett, C.N., 1994. "A unified framework for the study of anti-windup design." Automatica, 30, 1869-1883.

Skosgestad, S., 2002. "Simple analytic rules for model reduction and PID controller tuning." Journal of Process Control, 13 (2003), 291-309.

Visioli, A., 2003. "Modified anti-windup scheme for PID controllers." IEE Proc-Control Theory Appl., 150, 49-54.

Walgama, K. S., and Sternby, J., 1990. "Inherent observer property in a class of anti-windup compensators." Int. $J$. Control, 52, 705-724.

Walgama, K. S., Ronnback, S. and Sternby, J., 1992. "Generalisation of conditioning technique for antiwindup compensators." IEE Proc. D, 139, 109-118.

Zheng, A., Kothare, M.V. and Morari, ML, 1995. "Antiwindup design for internal model control." Int. J. Control, 60, 1015-1024.
HAYK MARKAROGLU received the B.Sc. degree from the Department of Electrical Engineering of the Faculty of Electrical Engineering of Yildiz Technical University, Istanbul, Turkey, in 2003. He is currently a M.S. student in the Control and Automation Engineering Program of the Institute of Science and Technology of Istanbul Technical University. His research interests are anti-windup control, fuzzy process control.

MUJDE GUZELKAYA received the B.Sc. degree from the Department of Electronics and Communication Engineering of the Faculty of Electrical Engineering of Istanbul Technical University, Istanbul, Turkey, in 1982 and M.S. and $\mathrm{Ph} . \mathrm{D}$. degrees from the Institute of Science and Technology of the same university in 1984 and 1990, respectively. She is currently a professor in Control Systems Division of the Department of Electrical Engineering of Istanbul Technical University. Her research interests are intelligent control, multivariable control and stochastic optimal control. Her e-mail address is gkaya@elk.itu.edu.tr and his Web-page can be found at www.elk.itu.edu.tr/ gkaya.

IBRAHIM EKSIN received the B.Sc., M.S. and Ph.D. degrees from the Department of Electrical Engineering of Bogazici University, Istanbul, Turkey, in 1976, 1979 and 1983, respectively. He has worked in Honeywell from 1983 to 1985 . He then joined Control Systems Division of the Department of Electrical Engineering of Istanbul Technical University and is currently working as a professor in the same division. $\mathrm{He}$ is the General Secretariat of NMO of IFAC. His research interests are intelligent control, optimal control and evolutionary computation. His e-mail address is eksin@elk.itu.edu.tr and his Web-page can be found at www.elk.itu.edu.tr/ eksin.

ENGIN YESIL received B.Sc. degree from the Department of Electrical Engineering of the Faculty of Electrical and Electronics Engineering of Istanbul Technical University, Istanbul, Turkey, in 1998 and M.S. degree from the Institute of Science and Technology of the same university in 2000 . He is currently a Ph.D. student and is working as a research assistant in the Control Systems Division of the Department of Electrical Engineering of Istanbul Technical University. His research interests are intelligent control, process control. His e-mail address is: yesil@elk.itu.edu.tr and his Web-page can be found at www.elk.itu.edu.tr/ yesil. 